PRÁTICAS EDUCATIVAS, MEMÓRIAS E ORALIDADES

Rev.Pemo - Revista do PEMO

\title{
A aplicabilidade das políticas públicas educacionais inclusivas para as pessoas com deficiência
}

\author{
Jeanne do Socorro Batista Aguiar ${ }^{i}$ \\ Secretaria de Estado da Educação, Macapá, AP, Brasil \\ Paula Soares Rodriguesii \\ Universidade Estadual do Pará, Belém, PA, Brasil
}

\begin{abstract}
Resumo
Este trabalho é resultado da inquietação da aplicabilidade e acesso das políticas públicas sobre a garantia à educação Inclusiva para as pessoas com deficiência e objetiva-se compreender as principais discussões fomentadas nas pesquisas sobre o tema. A metodologia que se utilizou foi a pesquisa qualitativa de revisão de literatura com foco no estado da questão. Os resultados identificaram limitações, sugestões, vantagens e benefícios das políticas públicas. As discussões apontaram para a relevância de fomento ao planejamento com estratégias, metas e avaliação. Concluímos que tais políticas são instrumentos do Estado democrático de direito não só para a melhoria dos indicadores educacionais, mas também para a permanência nas escolas e qualidade de vida de todos.
\end{abstract}

Palavras-chave: Educação Inclusiva. Política pública. Pessoa com Deficiência.

The applicability of inclusive public educational policies for people with disabilities

\begin{abstract}
This work is the result of the concern about the applicability and access of public policies on the guarantee of inclusive education for people with disabilities and aims to understand the main discussions fostered in research on the subject. The methodology used was a qualitative literature review research focusing on the state of the matter. The results identified limitations, suggestions, advantages, benefits of public policies. The discussions pointed to the relevance of fostering planning with strategies, goals, evaluation. We conclude that such policies are instruments of the democratic rule of law not only for the improvement of educational indicators, but also for the permanence in schools and for everyone's quality of life.
\end{abstract}

Keywords: Inclusive Education. Public Policy. People with Disabilities.

\section{Introdução}

Rev.Pemo, Fortaleza, v.3, n.1, e316343, 2021

DOI: https://doi.org/10.47149/pemo.v.6343

https://revistas.uece.br/index.php/revpemo

ISSN: 2675-519X

(c) (i) Esta obra está licenciada com uma Licença Creative Commons

Atribuição 4.0 Internacional. 
O presente trabalho sobre a análise de literatura de acordo com o estado da questão quanto à aplicabilidade das políticas educacionais inclusivas as pessoas com deficiência que se faz necessário em qualquer momento da escolaridade e perpassa por todas as modalidades de ensino, pois sempre haverá quem precise ser incluído em um determinado contexto, de acordo com as novas demandas sociais possa sensibilizar e quem sabe induzir os tomadores de decisão, a sociedade a promoverem as transformações necessárias. Assim, com esta prática buscar a tão sonhada democracia significativa e equitativa.

Acredita-se que as pesquisas científicas relatem as ações públicas acerca das políticas públicas inclusivas, haja vista que já se alcançou a inclusão de um número considerado de pessoas com deficiência, porém não se percebeu ainda na sociedade a mudança de atitude com relação a inclusão de fato e de direito com a participação ativa, destas na sociedade. Objetiva-se com este trabalho, compreender as principais discussões fomentadas nas pesquisas cientificas sobre as políticas públicas educacionais inclusivas.

Segundo Sobrinho (2013, p.1), "a educação é um bem público, imprescindível, direito de todos e dever do Estado, este deverá criar e oferecer condições efetivas para que isto se realize com a amplitude, a qualidade e a sustentabilidade necessárias e adequadas. Sendo bem público, a educação deve ser de qualidade. Esta é a base da discussão sobre políticas públicas.

Como bem é citado por Oliveira (2020, p. 32), "a adoção do termo "inclusão" não encerra o processo inclusivo, ela apenas avança e inicia esse percurso que segue em direção a uma pedagogia que consiga acolher as diferenças e as especificidades dos educandos".

Segundo Mantoan (2003. p. 97),

A educação inclusiva deve ser entendida como uma tentativa a mais de atender as dificuldades de aprendizagem de qualquer aluno no sistema educacional e com um meio de assegurar que os alunos, que apresentam alguma deficiência, tenham os mesmos direitos que os outros, ou seja, os mesmos direitos dos seus colegas escolarizados em uma escola regular.

Rev.Pemo, Fortaleza, v.3, n.1, e316343, 2021

DOI: https://doi.org/10.47149/pemo.v.6343

https://revistas.uece.br/index.php/revpemo

ISSN: 2675-519X

(c) (i) Esta obra está licenciada com uma Licença Creative Commons

Atribuição 4.0 Internacional. 
Portanto, diante das palavras da autora acima, a inclusão, tem uma armadilha: ao abstrairmos a diferença, tratando as pessoas igualmente, devido não ser necessário enfatizar as diferenças, ao invés de suas especificidades.

O referido tema é importante tanto socialmente, quanto cientificamente, pois tornase pertinente perpassar pelos documentos como leis, decretos, programas e resoluções que influenciaram ou influenciam a criação de leis e diretrizes inclusivas.

Segundo Oliveira (2020, p. 34), "Compreendendo as proposições como o documento da Unesco, podemos apontar que a inclusão é um processo abrangente que busca a modificação de atitudes discriminatórias, a fim de desenvolver uma sociedade inclusiva".

Freire (2008, p.5, apud OLIVEIRA, 2020, p. 32) contribuiu para essa discussão definindo inclusão:

[...] um movimento educacional, mas também social e político que vem defender o direito de todos os indivíduos participarem, de uma forma consciente e responsável, na sociedade de que fazem parte, e de serem aceitos e respeitados naquilo que os diferencia dos outros. No contexto educacional, vem, também defender o direito de todos os alunos desenvolverem e concretizarem as suas potencialidades, bem como de apropriarem as competências que Ihes permitam exercer o seu direito de cidadania, através de uma educação de qualidade, que foi talhada tendo em conta as suas necessidades, interesses e características.

Pontos positivos da pesquisa, no que tange as vantagens e benefícios que o estudo pôde proporcionar, percebeu-se o apontamento da necessidade de mudanças tanto à formação inicial como a formação permanente de educadores(as) com relação a sua prática, assim como de todos os envolvidos e, avaliação constante das políticas pelos órgãos de controle e até mesmo da sociedade, houve também a reflexão sobre as cotas para inserção no mercado de trabalho. O trabalho está estruturado com introdução, metodologia, resultados e discussões do estado da questão e conclusão.

\section{Metodologia}

A metodologia adotada na investigação com a pesquisa bibliográfica que possibilitou abordagem qualitativa, considerando a identificação e análise dos dados, 
devido a diversidade de indivíduos e período histórico. O método da pesquisa foi o Estado da Questão (EQ) que na oportunidade confirma as condições atuais na literatura científica sobre os objetos da investigação. A partir dessa problemática, objetivou-se compreender as principais discussões fomentadas nas pesquisas sobre as políticas públicas educacionais inclusivas.

Para Selltiz, et al., (1967, p.63 Apud GIL, 2002, p. 41),

Estas pesquisas têm como objetivo proporcionar maior familiaridade com 0 problema, com vistas a torná-lo mais explícito ou a constituir hipóteses. Pode-se dizer que estas pesquisas têm como objetivo principal o aprimoramento de ideias ou a descoberta de intuições.

Mais especificamente, busca-se apresentar o EQ acerca da temática "educação inclusiva, pessoa com deficiência e política educacional inclusiva". A respeito do propósito dessa metodologia de pesquisa. Nóbrega-Therrien e Therrien (2010, p. 34) afirmam que a "[...] finalidade do EQ é a de levar o pesquisador a registrar, com suporte em um rigoroso levantamento bibliográfico, como se encontra o tema ou o objeto de sua investigação no estado atual da ciência ao seu alcance".

Considerando a abordagem qualitativa tem-se demonstrado o importante papel do estudo do EQ. Trata-se da definição do objeto específico da investigação, dos objetivos da pesquisa e na posse dos dados se desenha a narrativa.

O estudo tem início com a pesquisa bibliográfica que tratam da temática, de posse dos trabalhos, haja uma seleção das mais relevantes, de modo a fundamentar claramente o conceito de Inclusão, Política Pública e Deficiência.

Conforme, Nóbrega-Therrien e Therrien, (2010, p. 34) "O pesquisador pode fazer uso de distintas fontes selecionadas mediante sua pertinência para o estudo em tela", logo se optou por realizar a coleta em duas bases de dados: Banco de Teses e Dissertações da Coordenação de Aperfeiçoamento de Pessoal de Nível Superior - BDTD e Scientific Electronic Library Online - SciELO.

Para a construção desta pesquisa, considerou-se as produções de duas bases de dados: a BDTD e a SciELO. As bases selecionadas foram por motivo de proporcionarem acesso gratuito e atuais, uma vez que a BDTD compõe teses e dissertações derivadas de

Rev.Pemo, Fortaleza, v.3, n.1, e316343, 2021

DOI: https://doi.org/10.47149/pemo.v.6343

https://revistas.uece.br/index.php/revpemo

ISSN: 2675-519X

(c) (i) Esta obra está licenciada com uma Licença Creative Commons

Atribuição 4.0 Internacional. 
pesquisas aprovadas por comissão de avaliação e, a SciELO oferece artigos qualificados, uma política rigorosa de ingresso e manutenção dos periódicos de sua base. Após a leitura superficial do resumo e das categorias, selecionaram-se 02 produtos no banco de dados da BDTD, cinco artigos na SciELO. Adiante têm-se as informações sobre os estudos considerados para o EQ separados pelas bases de dados.

Desse modo, a consulta à base da BDTD se deu no dia 05 de julho de 2021, os objetos de estudo foram duas dissertações disponíveis, inicialmente pelo descritor "política pública", obteve-se o resultado de 27.976, foi refeita a pesquisa com três descritores, "política pública" e "inclusão" e "deficiência", obteve-se o resultado de 477, com o filtro do idioma "português" encontra-se 464 resultados, com acréscimo do filtro com ano de defesa entre 2016 a 2020 , encontrou-se 224 resultados, com mais o filtro do assunto: inclusão e políticas públicas, obteve-se 4 resultados, sendo todas dissertações, a saber:

Quadro 1- Teses e dissertações da BDTD

\begin{tabular}{|c|c|c|c|c|}
\hline Autor(es) & Título & Tipo & Curso & $\begin{array}{c}\text { Instituição/ } \\
\text { ano }\end{array}$ \\
\hline $\begin{array}{l}\text { MARTINS, } \\
\text { Clarissa de } \\
\text { Andrade } \\
\text { Fernandes }\end{array}$ & $\begin{array}{c}\text { A inclusão de crianças } \\
\text { com deficiência na educação } \\
\text { infantil: políticas públicas na visão } \\
\text { dos professores. }\end{array}$ & Dissertação & $\begin{array}{l}\text { Mestrado em } \\
\text { Educação } \\
\text { Brasileira }\end{array}$ & $\mathrm{FCHS} / 2018$ \\
\hline $\begin{array}{l}\text { NEVES, } \\
\text { Regiane } \\
\text { Timoteo das }\end{array}$ & $\begin{array}{l}\text { Políticas públicas de inclusão de } \\
\text { alunos com deficiência de } 1994 \text { a } \\
\text { 2014: limites e perspectivas na } \\
\text { inclusão de alunos surdos no } \\
\text { município de Colombo-PR }\end{array}$ & Dissertação & $\begin{array}{l}\text { Mestrado em } \\
\text { Educação } \\
\text { Brasileira }\end{array}$ & $\begin{array}{l}\text { Universidade } \\
\text { Tuiuti do } \\
\text { Paraná/2016 }\end{array}$ \\
\hline $\begin{array}{l}\text { NASCIMENTO, } \\
\text { Élida Galvão } \\
\text { do }\end{array}$ & $\begin{array}{l}\text { Educação especial e instituição } \\
\text { educacional especializada: } \\
\text { história e políticas públicas. }\end{array}$ & Dissertação & $\begin{array}{l}\text { Mestrado em } \\
\text { Educação } \\
\text { Brasileira }\end{array}$ & $\begin{array}{c}\text { UNOESTE/ } \\
2018\end{array}$ \\
\hline $\begin{array}{l}\text { FLORES, } \\
\text { Andrezza } \\
\text { Santos }\end{array}$ & $\begin{array}{l}\text { Gestão escolar e educação } \\
\text { inclusiva: articulação entre o } \\
\text { atendimento educacional } \\
\text { especializado e o ensino regula }\end{array}$ & Dissertação & $\begin{array}{l}\text { Mestrado em } \\
\text { Educação } \\
\text { Brasileira }\end{array}$ & IBILCE/2018 \\
\hline
\end{tabular}

Fonte: Autoria própria (2021).

Excluído da análise por incompatibilidade com o objetivo proposto: A segunda dissertação da autora NEVES, "Políticas públicas de inclusão de alunos com deficiência de 1994 a 2014: limites e perspectivas na inclusão de alunos surdos no 
município de Colombo-PR," pois não consegui abri o arquivo na integra em site algum e, a 4ํㅡㄹ dissertação da autora FLORES, "Gestão escolar e educação inclusiva: articulação entre o atendimento educacional especializado e o ensino regular", porque não estava de acordo com o objetivo proposto do trabalho.

A consulta à base de dados da SciELO foi desenvolvida no dia 05 de julho de 2021. Os objetos de estudo todos os artigos científicos publicados entre 2016 e 2020, localizados inicialmente pelos descritores "política pública" e "inclusão" e "deficiência", todos os índices, obteve-se o quantitativo de 19 resultados, posteriormente foi refinada a busca com o filtro: Brasil, idioma português, ano de publicação de 2016 a 2020, então obteve-se o resultado 06 artigos.

De posse das produções, foram selecionados os trabalhos que tinham relação com o objetivo proposto, após a leitura minuciosa dos resumos e da estrutura, consideraram-se apenas 04 produções. O Quadro 2 apresenta as principais informações dos artigos selecionados. A saber:

\section{Quadro 2 - Artigos da SciELO}

\begin{tabular}{|c|c|c|c|}
\hline Autor(es) & Título & Revista & Ano \\
\hline $\begin{array}{l}\text { GARCIA, Fabiane } \\
\text { Maia; BRAZ, Aissa } \\
\text { Thamy Alencar Mendes. }\end{array}$ & $\begin{array}{l}\text { Deficiência visual: caminhos legais e } \\
\text { teóricos da escola inclusiva }\end{array}$ & $\begin{array}{l}\text { Ensaio: aval. pol. } \\
\text { públ. } \\
\text { educ. }\end{array}$ & 2020 \\
\hline $\begin{array}{l}\text { SIMONELLI, Angela } \\
\text { Paula; JACKSON FILHO, } \\
\text { José Marçal; TEIXEIRA, } \\
\text { Araiê Carolina; } \\
\text { OLIVEIRA, Beliza Andréia } \\
\text { de; FRIEBE, Emanuele } \\
\text { Caroline de } \\
\text { Lima; CANALI, Raquel } \\
\text { Del; BORDIGNON, } \\
\text { Tarciana Maria; } \\
\text { OLIVEIRA, Vanderléia } \\
\text { Pontes Marques de. }\end{array}$ & $\begin{array}{c}\text { Enquadramento da temática da } \\
\text { inclusão de pessoas com deficiência } \\
\text { no trabalho em Jornal de grande } \\
\text { circulação do estado do Paraná de } \\
1991 \text { a } 2006\end{array}$ & $\begin{array}{c}\text { Cadernos Brasileiros } \\
\text { de Terapia } \\
\text { Ocupacional }\end{array}$ & 2020 \\
\hline $\begin{array}{l}\text { ABREU, Tania Paim } \\
\text { Caldas de; VILARDO, } \\
\text { Maria Aglaé Tedesco; } \\
\text { FERREIRA, Aldo } \\
\text { Pacheco. }\end{array}$ & $\begin{array}{c}\text { Acesso das pessoas com deficiência } \\
\text { mental aos direitos e garantias } \\
\text { previstos na Lei Brasileira de } \\
\text { Inclusão por meio do Sistema Único } \\
\text { de Assistência Social. }\end{array}$ & Saúde em Debate & 2019 \\
\hline $\begin{array}{l}\text { BAPTISTA, Claudio } \\
\text { Roberto. }\end{array}$ & $\begin{array}{c}\text { Política pública, Educação Especial e } \\
\text { escolarização no Brasil }\end{array}$ & $\begin{array}{l}\text { Educação e } \\
\text { Pesquisa }\end{array}$ & 2019 \\
\hline
\end{tabular}

Rev.Pemo, Fortaleza, v.3, n.1, e316343, 2021

DOI: https://doi.org/10.47149/pemo.v.6343

https://revistas.uece.br/index.php/revpemo

ISSN: 2675-519X

(c) (i) Esta obra está licenciada com uma Licença Creative Commons

Atribuição 4.0 Internacional. 
PRÁTICAS EDUCATIVAS, MEMÓRIAS E ORALIDADES

Rev.Pemo - Revista do PEMO

\begin{tabular}{|l|c|c|c|}
\hline COSTA, Nilson do & Proteção social e pessoa com \\
Rosário; MARCELINO, & deficiência no Brasil & 2016 \\
Miguel Abud; DUARTE, & & & \\
$\begin{array}{l}\text { Cristina Maria } \\
\text { Rabelais; UHR, Deborah. }\end{array}$ & & & \\
\hline $\begin{array}{l}\text { LIMA, Stéfanie } \\
\text { Melo; LAPLANE, Adriana } \\
\text { Lia Friszman de. }\end{array}$ & $\begin{array}{c}\text { Escolarização de alunos com } \\
\text { autismo }\end{array}$ & $\begin{array}{c}\text { Revista Brasileira de } \\
\text { Educação Especial }\end{array}$ & 2016 \\
\hline
\end{tabular}

Fonte: Autoria própria (2021).

Excluído da análise por incompatibilidade com o objetivo proposto o artigo “Enquadramento da temática da inclusão de pessoas com deficiência no trabalho em Jornal de grande circulação do estado do Paraná de 1991 a 2006" e "Proteção social e pessoa com deficiência no Brasil".

Os estudos disseminados sobre a inclusão, nos anos compreendidos entre 2016 e 2020, revelam que essa temática sempre esteve presente, ainda que em quantidade limitada de estudos, conforme exposto no Quadro 3.

Quadro 3 - Evolução das pesquisas "política pública" “inclusão” “deficiência” por ano:

\begin{tabular}{|c|c|c|c|c|c|}
\hline Tipo de publicação & 2016 & $\mathbf{2 0 1 7}$ & $\mathbf{2 0 1 8}$ & $\mathbf{2 0 1 9}$ & $\mathbf{2 0 2 0}$ \\
\hline Teses & - & - & - & - & - \\
\hline Dissertações & - & - & 02 & - & - \\
\hline Artigos & 01 & - & - & 02 & 01 \\
\hline Subtotal & 01 & - & 02 & 02 & 01 \\
\hline Total & \multicolumn{5}{|c|}{$\mathbf{0 6}$} \\
\hline
\end{tabular}

Fonte: Autoria própria (2021).

Das 02 dissertações consideradas para a análise, as duas eram originárias do Programa de Pós-Graduação em Educação Brasileira (FCHS e UNOESTE), o que demonstra que os programas de Educação Brasileira o que mais investe na temática aqui em comento. Finalizada a demonstração dos produtos considerados para a análise do $\mathrm{EQ}$, agrupou-se em categorias no intuito de facilitar a discussão dos resultados.

$\mathrm{Na}$ exploração dos resultados, realizou-se a leitura e a releitura, detalhada do material, posteriormente os produtos foram categorizados e agrupados por semelhança temática, que no primeiro momento, apresentaram como principais temas: educação especial, educação inclusiva, política pública, inclusão, pessoa com deficiência. Após a análise, tais temáticas foram reagrupadas em três categorias emergentes: "Educação

Rev.Pemo, Fortaleza, v.3, n.1, e316343, 2021

DOI: https://doi.org/10.47149/pemo.v.6343

https://revistas.uece.br/index.php/revpemo

ISSN: 2675-519X

(c) (i) Esta obra está licenciada com uma Licença Creative Commons

Atribuição 4.0 Internacional. 
especial e educação inclusiva", "Política pública e inclusão" e "Política pública e pessoa com deficiência" (ver Quadro 4).

Quadro 4 - Categorização das produções selecionadas por bases de dados

\begin{tabular}{|c|c|c|}
\hline Categorias temáticas & Base de dados & Produções selecionadas \\
\hline Educação especial e Educação Inclusiva & BDTD & 01 \\
\cline { 2 - 3 } & SciELO & 01 \\
\hline Política Pública e inclusão & BDTD & 01 \\
\cline { 2 - 3 } & SciELO & 01 \\
\hline Política pública e Pessoa com Deficiência & BDTD & 06 \\
\cline { 2 - 3 }
\end{tabular}

Fonte: Autoria própria (2021).

Após baixar e ler os 06 resultados da pesquisa tanto na plataforma SciELO quanto na BDTD, adotou-se os seguintes critérios de seleção: a abordagem da referência está alinhada ao objetivo proposto ao presente artigo? A referência da pesquisa foi publicada em revista nacional qualificada? A referência está contida no recorte temporal estabelecido - preferencialmente referências com até 5 anos da data de publicação? A referência agrega à compreensão e ao encaminhamento do processo de produção científica, delimitando o alcance do EQ.

De posse da categorização, realizou-se a investigação acerca das pesquisas sobre educação inclusiva, na interface com as políticas públicas. A seguir, ratifica-se o cuidado ético desta obra em respeitar as ideias originais dos autores pesquisados citandoas de forma adequada.

\section{Resultados e Discussão}

Para melhor organização das discussões dos resultados, apresentam-se as reflexões desde as categorias emergentes da análise de conteúdo, quais sejam: 1) "Educação especial e educação inclusiva"; 2) "Política pública e inclusão" e 3) "Política pública e pessoa com deficiência". Com embasamento teórico de autores como: Baptista 
(2019), Costa (2010), Fávero (2013), Mendes (2010), Martins (2018), Prieto (2006), Pessotti (1984), Rebelo e Kassar (2018), Sassaki (1997), Miller e Surel (2002) e outros.

A categoria Educação especial e educação inclusiva abrange os diferentes níveis e graus do sistema de ensino. Há tentativas isoladas referentes à Educação Especial, somente no século XX no Brasil, aproximadamente por volta do ano de 1970, as escolas comuns passaram a aceitar crianças com deficiências em ambientes como sala comum ou nas salas especiais.

Sobre a Constituição de 1988, os autores pesquisados foram unânimes em definir que "a CF/88 foi o grande marco na história da Educação do país, estabelecendo algumas garantias às pessoas com deficiência e abrindo portas para a elaboração de novas políticas inclusivas" (MARTINS, 2018, p.42). Assim, fortaleceu os direitos das pessoas com deficiência, garantindo o acesso e a igualdade de oportunidades.

Três autores discorreram sobre a Educação Inclusiva, a Lei de Diretrizes e Bases da Educação Nacional - LDB de 1996, foi com a LDB que se estabeleceu o marco da educação inclusiva no Brasil, onde expressa no artigo $3^{\circ}$, inciso I, o princípio da "igualdade de condições para o acesso e permanência na escola", e em seu artigo $4^{\circ}$, inciso III do Título III, o "atendimento educacional especializado gratuito aos educandos com necessidades especiais, preferencialmente na rede regular de ensino".

Conforme, Mantoan (2015, p. 43), "A Política Nacional de Educação Especial na Perspectiva da Educação Inclusiva, instaura um novo marco político e pedagógico na educação do país".

Através da Convenção Internacional de Direitos da Pessoa com Deficiência, o Brasil no art. $4^{\circ}$ se comprometeu a adotar medidas legislativas, administrativas necessárias a realização dos direitos e garantias, assegurando e de modo a promover em condições de igualdade o exercício dos direitos. (BRASIL, 2009b)

As leis que regulamentam tais modalidades de ensino, nada mais são segundo Martins (2018, p. 55), a busca do direito de ser diferente.

Segundo Baptista (2011, p.7) 


\begin{abstract}
Durante muito tempo, como ocorre ainda na atualidade, é difundida a compreensão de que a problemática da escolarização do aluno com deficiência estaria associada à sua suposta incapacidade e se traduziria em uma palavra: encaminhamento. Esse ideário parece partir da suposição de que, caso houvesse os cuidados pertinentes, estaríamos protegidos de tudo aquilo que era frequente: crianças encaminhadas, muitas vezes, precocemente e sem diagnóstico para as classes especiais. [...] Considero tratar-se de uma falácia, pois não existe um dispositivo em modo dissociado de sua história. A classe especial, em função de sua existência, contribuiu para a configuração de um grupo destinado a esse atendimento, pois, a partir da existência desse tipo de classe, a escola passa a ter para onde encaminhar aqueles que estão em descompasso com a condição de aluno considerado ideal.
\end{abstract}

Também, não se trata de negar as limitações de natureza física, mental ou intelectual, mas sim, reconhecer, erigir condições culturais, sociais, cientificas e jurídicas à inclusão e consequentemente à superação das pessoas com deficiência.

Considerando o índice de matrículas, a distribuição nos serviços educacionais, de acordo com a análise de Rebelo e Kassar (2018, p.288), com base no lapso temporal que vai de 1974 a 2014, identificam que o contingente de matrículas tem aumentado. Ao referirem-se às matrículas dos alunos com deficiência, afirmam:

\begin{abstract}
No geral, é interessante notar que, em 40 anos, o número de matrículas de alunos da Educação Especial aumentou nove vezes, enquanto o número de matrículas da população em geral na Educação Básica aumentou apenas 2,67 vezes. Por outro lado, a proporção das primeiras em relação ao total de matrículas na educação básica não chegou a $2 \%$ dos registros.
\end{abstract}

$\mathrm{Na}$ categoria "Política pública e inclusão", compreende-se como processo contínuo associado à ação pública, de acordo com Muller e Surel (2002, p. 10), esses estudiosos acreditam que política pública não serve para resolver problemas.

A Política Nacional para a Inclusão da Pessoa com Deficiência estabelece em seu artigo $1^{\circ}$ que política pública, "compreende o conjunto de orientações normativas que objetiva assegurar o pleno exercício dos direitos individuais e sociais das pessoas portadoras de deficiência". Todos esses dispositivos "possibilitam estabelecer o horizonte das políticas educacionais, de modo que se assegure a igualdade de oportunidades e a valorização da diversidade no processo educativo" (BRASIL, 2001, p. 18).

Sassaki (1997, p. 39), conceitua inclusão social como: 


\begin{abstract}
O processo pelo qual a sociedade se adapta para poder incluir em seus sistemas sociais gerais, pessoas com necessidades especiais e simultaneamente, estas se preparam para assumir seus papeis na sociedade. A inclusão social constitui, então, um processo bilateral no qual as pessoas, ainda excluídas, e a sociedade buscam, em parceria, equacionar problemas, decidir sobre soluções e efetivar a equiparação de oportunidades para todos
\end{abstract}

outros, observou-se que a pessoa com deficiência tem direito constitucional a educação de qualidade e adequada, visando sua habilitação e ou reabilitação. A lei nº13.146/2015 (BRASIL, 2015, p.1), em seu artigo segundo, define pessoa com deficiência como:

[...] aquela que tem impedimento de longo prazo de natureza física, mental, intelectual ou sensorial, o qual, em interação com uma ou mais barreiras, pode obstruir sua participação plena e efetiva na sociedade em igualdade de condições com as demais pessoas.

Já Vigotski (2014, In: MARTINS, 2018, p.13) "refere-se à criança com deficiência como aquela que tem um desenvolvimento diferente, e não menor, do que a criança sem deficiência, devendo receber importantes estímulos para que supere os limites dados a elas". "[...] não atinge[m] as grandes massas fanatizadas pelas hierarquias religiosas e muito menos os donos do poder político-econômico, nutrido por tal fanatismo." (In: MARTINS, 2018, p.33)

As pesquisas que tematizaram a educação inclusiva nos permitem contribuição teórico-crítica para a compreensão sobre a ênfase que os pesquisadores evocaram nos seus trabalhos acadêmicos. Com objetivo distinto de compreensão das principais discussões fomentadas nas pesquisas sobre as políticas públicas educacionais inclusivas, todas as pesquisas tinham em comum o foco na educação inclusiva, política pública e pessoa com deficiência, alguns utilizaram os mesmos autores como Baptista, Mantoan, Manzzotta e Manzzini. Portanto, constatou-se que as políticas públicas surgem para garantir o conhecimento formal e o desenvolvimento pleno às pessoas com deficiências. Apesar de sua aplicabilidade ser deficiente e o Ministério da Educação ter apontado o aumento do número de matrículas dessa clientela, não se pode perder o foco de uma educação de qualidade para que de fato o aluno conquiste a autonomia, a cidadania, o mercado de trabalho e o lazer.

Rev.Pemo, Fortaleza, v.3, n.1, e316343, 2021

DOI: https://doi.org/10.47149/pemo.v.6343

https://revistas.uece.br/index.php/revpemo

ISSN: 2675-519X

(c) (i) Esta obra está licenciada com uma Licença Creative Commons

Atribuição 4.0 Internacional. 


\section{Considerações finais}

Ao iniciar esta pesquisa, pretendia-se compreender as principais discussões fomentadas nas pesquisas sobre as políticas públicas educacionais inclusivas a partir do $E Q$ de pesquisas desenvolvidas a respeito da inclusão a pelo menos nos últimos cinco anos. Salientando as nuances relevantes que fomentaram a realização dessa proposta, bem como, seu propósito, possíveis benefícios, problemas, dificuldades, conquistas e viabilidade. Para contemplar esse anseio, realizaram-se estudos de cunho bibliográfico e pesquisa de campo criteriosa.

Constatou-se avanços no que se refere aos aspectos legais e formais até a lei brasileira de inclusão - LBI (BRASIL, 2015), limitações e sugestões e uma das sugestões é de que o sucesso das políticas está relacionado com a equipe e a qualidade dos recursos humanos. Já quanto as limitações foram inúmeras acerca das condições culturais, sociais, e ou jurídicas. Todas as pesquisas tinham a política pública com o objetivo de apenas ofertar a inclusão para fins estatísticos de inclusão no ensino regular.

Dentro desse contexto alguns autores defendiam que os documentos discorrem sobre: aumento do acesso, diminuição da exclusão social; formação continuada de professores; e outros.

Com a revisão de literatura percebeu-se principalmente que segundo Mantoan (2003), "a inclusão é uma provocação, cuja intenção é melhorar a qualidade do ensino das escolas, atingindo a todos que fracassem em suas salas de aula". E assim, conseguir um mundo e uma sociedade melhor para todos. Constatou-se ainda que as políticas públicas com ênfase ao público da educação especial, beneficia a garantia dos alunos o acesso ao ensino regular de ensino, incluir também quer dizer: democratizar condições para permanência, para que não haja a evasão escolar, com relação a falta de condições necessárias para melhor atender esses alunos com deficiências. Enfim, através da pesquisa sobre as mais diversas temáticas se colabora com o conhecimento, esta prática precisa ser crítica para que se obtenha a produção de conhecimento para a mudança ou melhoria da educação e consequentemente da realidade. 
Na concepção de Arendt (2005, p.247),

\begin{abstract}
"a educação é o ponto em que decidimos se amamos o mundo o bastante para assumirmos a responsabilidade por ele. É, também, onde decidimos se amamos nossas crianças o bastante para não expulsá-las de nosso mundo e abandoná-las a seus próprios recursos, preparando-as, em vez disso, com antecedência para a tarefa de renovar um mundo comum."
\end{abstract}

Com base na ideia da filósofa, as categorias citadas possuem um sentido e ideia

única, abranger tanto a inclusão, quanto as políticas públicas, as pessoas com deficiência, garantia de direitos, juntamente com as pesquisas, para gerar muito mais conhecimentos diante deste assunto de grande relevância para a sociedade.

Principalmente, a pensadora nos chama para refletir quanto à importância e ao cuidado que os professores devem ter quanto às crianças e ao mundo em que vivemos.

De acordo com Silva, et al, $(2020$, p.3)

"os resultados apontam para um Plano Nacional de Educação com um olhar sobre a coletividade, norteando perspectivas de crescimento progressivo à educação inclusiva, posto que há uma necessidade de maximizar os incentivos financeiros voltados para políticas de inclusão. Sobretudo, priorizar as dimensões formativas do profissional, adequando-os dentro do contexto escolar e suas pluralidades."

Para FIALHO e SOUSA (2020, p.18), a gestão da qualidade na educação contempla a participação democrática e se configura como a ênfase pautado em um aprendizado sem interrupções regrado pela convivência e pelo respeito às diferenças, da introdução de ambientes de discussão e determinação coletiva, gerenciados por líderes articuladores capacitados, que visam a excelência na educação.

Este trabalho não se conclui, abre margem para que estudos sejam realizados e possam propiciar um contributivo novo e ainda maior na restituição da baixa qualidade da educação inclusiva e de posse das bases com relação à legislação e à teoria, se oriente através das políticas e das práticas tão importantes para que os órgãos públicos e os profissionais educacionais sejam capazes de atender e acolher o público em debate, assim, viabilizar de fato condições de uma educação com foco na perspectiva inclusiva.

\title{
Referências
}

Rev.Pemo, Fortaleza, v.3, n.1, e316343, 2021

DOI: https://doi.org/10.47149/pemo.v.6343

https://revistas.uece.br/index.php/revpemo

ISSN: 2675-519X

(c) (i) Esta obra está licenciada com uma Licença Creative Commons

Atribuição 4.0 Internacional. 
ABREU, Tania Paim Caldas de; VILARDO, Maria Aglaé Tedesco; FERREIRA, Aldo Pacheco. Acesso das pessoas com deficiência mental aos direitos e garantias previstos na Lei Brasileira de Inclusão por meio do Sistema Único de Assistência Social. RIO DE JANEIRO, V. 43, N. ESPECIAL 4, P. 190-206, DEZ 2019. Disponível em: https://www.scielo.br/j/sdeb/a/W3wFYpZGS6cyJhLvvYkSQ8C/?lang=pt\&format=pdf Acesso em: 25 de mar. 2021

ARENDT, H. Entre o passado e o futuro. Tradução Mauro W. Barbosa. 5. ed. São Paulo: Perspectiva, 2005.

BAPTISTA, Claudio Roberto. Ação pedagógica e educação especial: a sala de recursos como prioridade na oferta de serviços especializados. Revista Brasileira de Educação Especial, Marília, v. 17, n. esp. p. 59-76, 2011. Disponível em:

https://www.scielo.br/j/ep/a/8FLTQYvVChDcF77kwPHtSww/?lang=pt\&format=pdf Acesso em: 25 de mar. 2021

BRASIL. Constituição da República Federativa do Brasil de 1988. Brasília, DF: 1988. Disponível em: http://www.planalto.gov.br/ccivil_03/constituicao/constituicao.htm. Acesso em: 28 mar. 2021.

BRASIL. Lei no 8.069, de 13 de julho de 1990. Estatuto da criança e do adolescente. Brasília, DF: 1990. Disponível em: http://www.planalto.gov.br/ccivil_03/leis//8069.htm Acesso em: 18 mar. 2021.

BRASIL. Ministério da Educação e Cultura. Secretaria de Educação Especial. Política nacional de educação especial. Brasília, DF: MEC, 1994.

BRASIL. Lei n. 10172, de 10 de janeiro de 2001. Plano Nacional de Educação PNE/Ministério da Educação. Brasília, DF: INEP, 2001.

BRASIL. Política nacional de educação especial na perspectiva da educação inclusiva. Revista Inclusão, Brasília, DF, v. 4, n. 1, p. 7-17, jan./jun. 2008.

BRASIL. Decreto ํㅜ 6.949, de 25 de agosto de 2009b. Promulga a Convenção Internacional sobre os Direitos das Pessoas com Deficiência e seu Protocolo Facultativo, assinados em Nova York, em 30 de março de 2007. Diário Oficial da União, Brasília, DF, n. 163, ago. 2009.

BRASIL. Ministério da Educação. Conselho Nacional de Educação. Plano nacional de educação (PNE). INEP, Brasília, DF, 2014. 
BRASIL. Lei no 13.146, 2015. Lei Brasileira de Inclusão. Disponível em: http://www.planalto.gov.br/ccivil_03/_ato2015-2018/2015/lei//13146.htm acesso em: 05 de mar. 2021

FIALHO, Lia Fiuza; SOUSA, Francisca Genifer Andrade de. Juventudes em políticas públicas o estado da questão em pesquisas cearenses (2010-2016). 2020. V.15. nำ1. Disponível em: https://proxy.furb.br/ojs/index.php/atosdepesquisa/article/view/7457 Acesso em: 25 de mar. 2021.

FREIRE, Sofia. Um olhar sobre a inclusão. Revista da educação. V.XVI, n.1, p.5-20, 2008. Disponível em:

https://repositorio.ul.pt/bitstream/10451/5299/1/Um\%20olhar\%20sobre\%20a\%20Inclus\% c3\%a3o.pdf Acesso em: 25 de mar. 2021.

GARCIA, Fabiane Maia; BRAZ, Aissa Thamy Alencar Mendes. Deficiência visual: caminhos legais e teóricos da escola inclusiva. Artigo. Ensaio: Avaliação e Políticas Públicas em Educação Set 2020, Volume 28 № 108 Páginas 622 - 641 Disponível em: https://www.scielo.br/j/ensaio/a/6D8gzB5Dd7vnLG3FXmvN4bw/?lang=pt\&format=pdf Acesso em: 25 de jun. 2021.

GIL, Antônio Carlos. Como Elaborar Projeto de Pesquisa. 4. ed. São Paulo: Atlas, p.176, 2002.

LAKATOS, E. M.; MARCONI, M. De A. Fundamentos De Metodologia Científica. 7. Ed. São Paulo: Atlas, 2010.

KASSAR, Monica Magalhães. Educação especial na perspectiva da educação inclusiva: desafios da implantação de uma política nacional. Educar em Revista, Curitiba, v. 41, p. 61-79, 2011. Disponível em: Acesso em: 25 mar. 2018.

MANTOAN, Maria Teresa Égler. Inclusão escolar: o que é? Por quê? Como fazer? São Paulo: Moderna, 2003, 64p.

MANTOAN, Maria Teresa Égler. Inclusão escolar: o que é? Por quê? Como fazer? São Paulo: Summus, 2015.

MAZZOTTA, M. J. S. Educação especial no Brasil: história e políticas públicas. São Paulo: Cortez, 2011.

MARTINS, Clarissa de Andrade Fernandes. A inclusão de crianças com deficiência na educação infantil: políticas públicas na visão dos professores. 2018. $151 \mathrm{f}$. Dissertação (Mestrado em Planejamento e Análise de Políticas Públicas) - Faculdade de Ciências Humanas e Sociais, Universidade Estadual Paulista "Júlio de Mesquita Filho", 
Franca, 2018. Disponível em:

https://repositorio.unesp.br/bitstream/handle/11449/157210/Martins_CAF_me_fran.pdf?s equence=3\&isAllowed=y Acesso em: 05 de mar. de 2021.

MULLER, Pierre; SUREL, Ives. Análise das políticas públicas. Pelotas, Educat, 2002.

NÓBREGA-THERRIEN, S. M.; THERRIEN, J. O estado da questão: aportes teóricometodológicos e relatos de sua produção em trabalhos científicos. In: FARIAS, I. M. S.; NUNES, J. B. C.; NÓBREGA-TERRIEN, S. M. (Orgs.). Pesquisa científica para iniciantes: caminhando no labirinto. Fortaleza: UECE, 2010.p. 33-51.

OLIVEIRA, Rita Izabel Alves. Educação inclusiva PPP participativo: diálogos. 2020. Disponível em:

https://tede2.pucsp.br/bitstream/handle/23362/2/Rita\%20lsabel\%20Alves\%20Oliveira.pdf Acesso em: 25 de mar. 2021

REBELO, Andressa Santos; KASSAR, Mônica Magalhães. Indicadores educacionais de matrículas de alunos com deficiência no Brasil (1974-2014). Estudos em Avaliação Educacional, São Paulo, v. 29, n. 70, p. 276-307, jan./abr. 2018.

SASSAKI, R. K. Inclusão: construindo uma sociedade para todos. Rio de Janeiro: WVA, 1997.

SILVA, Joselma Ferreira Lima e, et al. Um olhar sobre a educação inclusiva no PNE 2014-2024: desafios e perspectivas. Rev. PEMO, Fortaleza, v. 2, n. 1, p. 1-14, 2020. Disponível em: https://revistas.uece.br/index.php/revpemo/article/view/3514/3151 Acesso em: 22 mar. 2021.

SOBRINHO, José Dias. Educação superior: bem público, equidade e democratização. Rev. Avaliação, Campinas; Sorocaba, SP, v.18, n. 1, p.107-126 mar. 2013. Disponível em: http://periodicos.uniso.br/ojs/index.php/avaliacao/article/view/1573/1496 Acesso em: 29 set. 2021.

UNESCO. Declaração de Salamanca sobre princípios, política e práticas na área das necessidades educativas especiais. Salamanca, Espanha, 1994.

i Jeanne do Socorro Batista Aguiar, https://orcid.org/0000-0002-7949-8221

Governo do Estado do Amapá. Secretaria de Estado da Educação. Núcleo de Educação Especial.

Pedagoga pela Universidade Federal do amapá (2008), Pós-graduação em educação, Faculdade Atual.

Atualmente é professora estadual, Mestranda em Planejamento em Políticas Públicas pela

Universidade estadual do Ceará e advogada (OAB/AP n.4447).

Rev.Pemo, Fortaleza, v.3, n.1, e316343, 2021

DOI: https://doi.org/10.47149/pemo.v.6343

https://revistas.uece.br/index.php/revpemo

ISSN: 2675-519X

(c) (i) Esta obra está licenciada com uma Licença Creative Commons

Atribuição 4.0 Internacional. 
PRÁTICAS EDUCATIVAS, MEMÓRIAS E ORALIDADES

Rev.Pemo - Revista do PEMO

Contribuição de autoria: pesquisa na base de dados, contribuição na elaboração da introdução, elaboração do resumo, elaboração da metodologia e análise das categorias políticas públicas, educação especial e inclusiva, deficiência, elaboração das considerações finais e a revisão textual. Lattes: http://lattes.cnpq.br/4811458965273391

E-mail: jeanneaguiap@gmail.com

ii Paula Soares Rodrigues, https://orcid.org/0000-0002-8026-908X

Universidade estadual do Pará. Secretaria de Educação do Estado.

Pedagogia pela universidade paulista (2017), especialista em educação especial e inclusiva pela Faculdade FACEL, Assessora pedagógica da Universidade Estadual do Pará.

Contribuição de autoria: contribuição na elaboração das considerações finais.

Lattes: http://lattes.cnpq.br/5034376270742578

E-mail: soares.rodrigues@aluno.uece.br

Editora responsável: Cristine Brandenburg

Especialista ad hoc: José Antônio Gabriel Neto

\section{Como citar este artigo (ABNT):}

AGUIAR, Jeanne do Socorro Batista; RODRIGUES, Paula Soares. A aplicabilidade das políticas públicas educacionais inclusivas para as pessoas com deficiência. Rev. Pemo, Fortaleza, v. 3, n. 1, e316343, 2021. Disponível em:

https://doi.org/10.47149/pemo.v3i1.6343

Recebido em 26 de março de 2021.

Aceito em 29 de abril de 2021.

Publicado em 30 de abril de 2021.

Rev.Pemo, Fortaleza, v.3, n.1, e316343, 2021

DOI: https://doi.org/10.47149/pemo.v.6343

https://revistas.uece.br/index.php/revpemo

ISSN: 2675-519X

cc) (i) Esta obra está licenciada com uma Licença Creative Commons

Atribuição 4.0 Internacional. 